\title{
International trade and business cycle synchronization in Poland, the European Union and the Euro Zone
}

\author{
Piotr Misztal ${ }^{1}$
}

ABSTRACT

The analysis of business cycle synchronization levels has become a key point in the discussion of the processes of international economic integration. Economists show a particular interest in analyzing the frequency of processes of business cycle convergence and divergence (decoupling) in the European Union, especially in the Euro Zone. One of the factors determining business cycle convergence in economies is the intensity and structure of international trade.

The aim of this paper is to analyze the influence exerted by international trade over the synchronization of business cycles in Poland, the European Union and the Euro Zone from 1995 to 2011. The analytical methods employed here encompass a review of the literature on macroeconomics and international finance, as well as econometric models (such as the Vector Autoregression Model). The results of empirical research indicate that an increase in trade turnover does not necessarily lead to greater business cycle synchronization in the economies under analysis. In fact, the impact of an increase in countries' turnover on the synchronization of their business cycles depends predominantly on the structure of trade turnover and not solely on the intensity of trade.

KEY WORDS: $\quad$ business cycle; international trade; economic integration

JEL Classification:

E32, F14, F15

${ }^{1}$ The Jan Kochanowski University in Kielce, Poland

\section{Introduction}

The analysis of business cycle synchronization levels, i.e., the correlation of the periodic component of gross domestic product (GDP), has become a key point in the discussion of the processes of international economic integration. Economists show a particular interest in analyzing the frequency of the processes of business cycle convergence and divergence (decoupling) in the European Union, especially in the Euro Zone.

Thus, a question arises as to whether business cycles

Correspondence concerning this article should be addressed to: Piotr Misztal, The Jan Kochanowski University in Kielce, Faculty of Management and Administration, Świętokrzyska Street 21, 25-369 Kielce, Poland, e-mail: misztal@tkdami.net in the Euro Zone are becoming more or less synchronized over time. If the European economy is truly in the process of economic divergence, pursuing a common economic policy, e.g., monetary policy, might not be equally effective from the perspective of each country or region in the European Union.

One of the factors determining economies' business cycle convergence is the intensity and structure of international trade. Nevertheless, considering existing economic theory, the influence of two nations' trade on the synchronization of their business cycles is not well-defined. Kenen (1969) was the first to suggest that highly diversified economies with a high percentage of intra-industry trade experience asymmetric shocks fairly infrequently. On the other hand, 


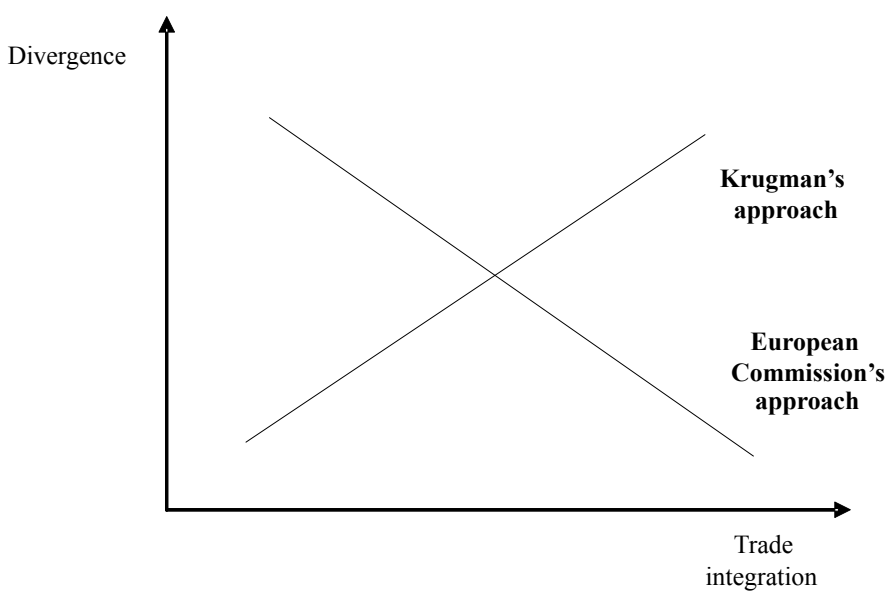

Figure 1. The influence of trade integration on business cycle divergence in light of the views of P. Krugman and the European Commission (Grigoli, 2011).

Krugman (1991) claimed that a country's susceptibility to asymmetric shocks increases as economies become more integrated, causing a rise in their specialization [Fig. 1].

These two opposing attitudes towards the influence of greater international trade integration on countries' specializations and business cycle convergence are known as the views of the European Commission and Krugman, respectively.

\section{The nature and main determinants of business cycle synchronization}

The degree of business cycle synchronization between two countries or regions is defined as the convergence of their economic growth rates over time, which is characterized by the correlation of the periodic component of real GDP. The level of business cycle synchronization is determined by many endogenous factors, the most important of which are the intensity of trade, the degree of similarity between economic structures, the level of similarity of monetary and fiscal policy, and the level of financial integration, among others.

According to the theory, it is possible for trade integration to have a bidirectional impact on the correlation of business cycles. On the one hand, if the demand channel is a dominating factor in a country's business fluctuations, an increase in the level of international trade integration may contribute to a rise in the level of business cycle correlation. On the other hand, if the factors connected with a given sector of the economy are those exerting the dominant impact on a business cycle, an increase in trade turnover between countries may lead to an increase or a decrease in the level of business cycle correlation, depending on the significance of intra- and inter-industry trade.

If inter-industry trade dominates in trade turnover, the rise in specialization in different industry sectors renders the influence of trade integration on business cycle synchronization negative. If, however, intra-industry trade prevails in countries' trade turnovers, the commodity structures of trade in the countries under analysis are approximate, which may exert a positive influence of trade integration on business cycle synchronization [Fig. 2.].

In essence, the total effect of an increase in the intensity of international trade on business cycle correlation is equivocal and depends on the level of economic development of the countries under analysis.

According to Imbs (2004), the level of similarity of economic (industrial) structures and the degree of specialization both exercise influence over the level of business cycle synchronization because economic shocks in a given industrial sector cause a greater in- 


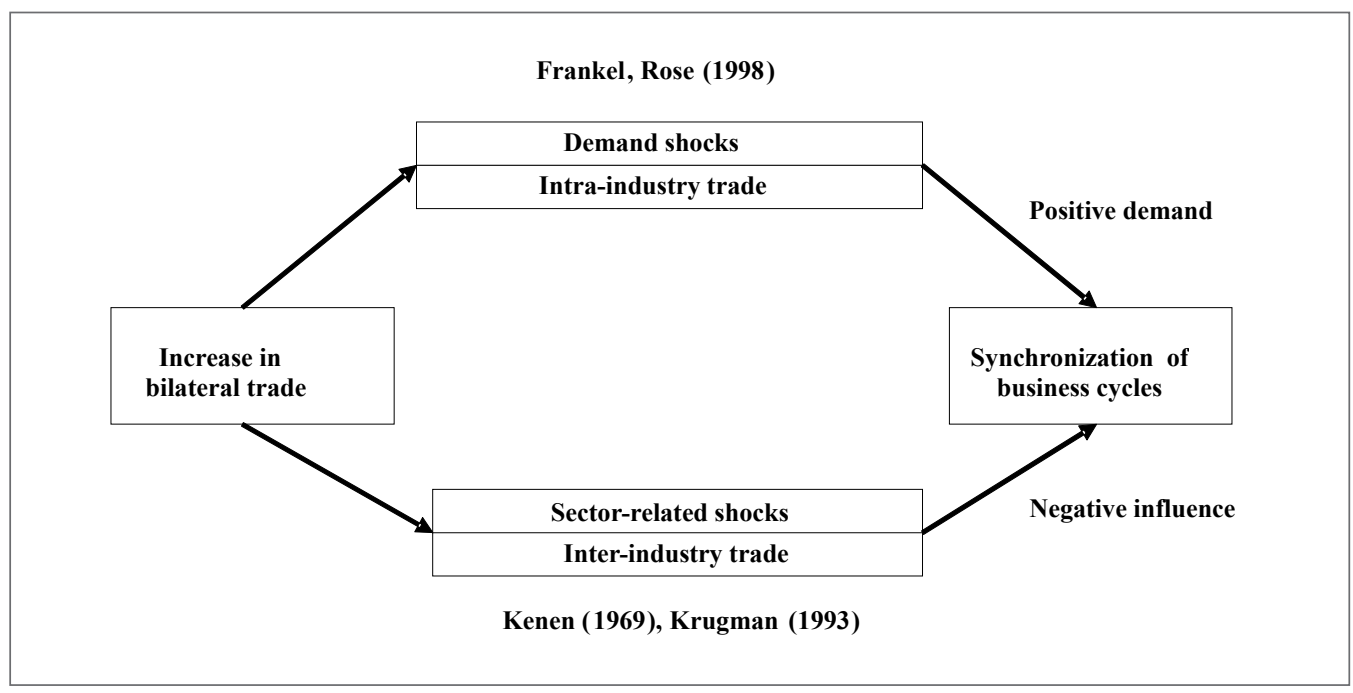

Figure 2. Channels through which the intensity of international trade exerts influence on business cycle synchronization (Rana, Cheng \& Chia, 2011).

crease in business cycle synchronization in countries with similar production structures, although not in economies with asymmetric production structures.

De Haan, Inklaar and Jong-a-Pin (2008) claim that if business cycles in countries with a monetary union are not convergent enough, the adopted monetary policy may not be optimal for each country concerned.

\section{Results of selected empirical analyses concerning business cycle synchronization}

The latest economic literature on international trade focuses mainly on the issue of the influence of international trade integration on the synchronization of business cycles (Akin, 2006).

Empirical research on the issue in question is based on two divergent approaches. One group of empirical studies is focused on analyzing the degree of business cycle synchronization over time in chosen countries or groups of countries, while the second group focuses on analyzing the most important determining factors in the level of business cycle synchronization in various economies.

Frankel and Rose (1998) proved the existence of a significant positive relationship between the intensity of international trade and business cycle correlation in the member states of the Organization for Economic
Co-operation and Development (OECD) from 1959 to 1993. Kenen (2000) claimed, however, that the results of empirical research conducted by Frankel and Rose (1998) should be taken with caution, as a high correlation of production in two different countries leads to an increase in the intensity of trade ties between those countries, but does not necessarily limit the number of asymmetric shocks in those economies.

Having analyzed the relationship between the intensity of international trade and the synchronization of business cycles using data from 21 OECD countries in the period between 1970 and 2003, De Haan, Inklaar and Jong-A-Pin (2005) confirmed the positive impact of the intensity of international trade on business cycle synchronization, although the effect was much less intense than Frankel and Rose (1998) had suggested.

The outcome of the conducted empirical research showed that trade integration was the main factor contributing to the synchronization of business cycles in Islamic countries, especially in the period between 1990 and 2005. Moreover, the similarity of the fiscal and monetary policies as well as countries' convergent economic structures had a significant and positive influence on the synchronization of business cycles (Karimi \& Pirasteh, 2009).

Calderón, Chong and Stein (2002) analyzed the impact of the intensity of international trade on business 
cycle synchronization in 147 countries between 1960 and 1999. Their study demonstrated that countries characterized by a greater intensity of bilateral trade were marked by a higher degree of business cycle synchronization and that the influence of trade integration on business cycle synchronization was higher in economically developed countries than in developing countries. Moreover, it was proven that the greater the degree of production structure asymmetry among the countries under analysis, the weaker the influence of the trade intensity on business cycle correlation.

In contrast, the results of empirical analyses encompassing 12 East Asian countries by Shin and Wang (2003) demonstrated that intra-industry trade was the main factor contributing to business cycle synchronization in those economies. Nonetheless, the intensification of international trade itself does not necessarily lead to greater business cycle synchronization, which results from the fact that an increase in countries' total trade turnover is usually accompanied by the development of intra-industry trade, which in turn leads to specialization and diversification of production structures in particular countries (Lubiński 2007).

Bayoumi and Eichengreen (1992) claim that European Union member states can be divided into two groups:. dominating (core) member states, where comparable economic shocks occur, and peripheral countries, which experience asymmetric shocks. In dominating states, the structure of the economy is highly diversified and the intra-industry trade very intense, whereas the peripheral states are highly specialized in inter-industry trade.

Conversely, in line with the results of research carried out by Krugman (1991), the process of economic integration leads to more asymmetric business fluctuations, which results in lesser synchronization of business cycles. The results of a survey by Camacho, PerezQuiros, and Saiz (2006) also suggest that economic integration causes increased regional concentration of economic activity, which consequently leads to sectorrelated or regional economic shocks, thus increasing the probability of occurrence of asymmetric shocks or divergent business cycles.

In conclusion, the outcome of the overwhelming majority of empirical analyses demonstrates that the influence of an increase in countries' trade turnover on the synchronization of their business cycles is not only related to the intensity of trade relationships but also to the structure of trade. In other words, if countries' trade turnovers are dominated by intra-industry trade, symmetric shocks are to be expected in these countries, as well as a greater synchronization in business cycles. However, if countries' trade turnovers are dominated by inter-industry trade, more frequent asymmetric shocks and lesser business cycle synchronization are to be expected (Kose \& Yi, 2005).

\section{Model-based analysis of international trade against business cycle synchronization}

As presented in the economic literature, the influence of trade integration on the synchronization of business cycles in countries or groups of countries is predominantly measured using a model developed by Frankel and Rose (1998), which is represented by the following equation:

$\operatorname{Corr}_{i j t}=c+\alpha$ Trade $_{i j t}+\varepsilon_{i j t}$

where:

Corr $_{i j t}$ - synchronization of business cycles in countries $i$ and $j$ in period $t$;

Trade $_{i j t}$ - intensity of trade in countries $i$ and $j$ in pe$\operatorname{riod} t$

$\alpha$ - coefficient of the influence of trade intensity in countries $i$ and $j$ on the synchronization of their business cycles;

- absolute term of the equation;

$\varepsilon_{i j t}$-random parameter.

The degree of business cycle synchronization in countries is measured by the Business Cycles Synchronization (BCS) index developed by Frankel, Rose (1998), and Akin (2006), expressed by the following equation:

$\operatorname{corr}_{i j}=\frac{\operatorname{cov}\left(y_{i}^{c}, y_{j}^{c}\right)}{\sqrt{\operatorname{var}\left(y_{i}^{c}\right) \operatorname{var}\left(y_{j}^{c}\right)}}$

where:

$y_{i}^{c}-$ logarithm of the real rate of the gross domestic product in country $i$, de-trended with the HodrickPresscott filter;

$y_{j}^{c}$ - logarithm of the real rate of the gross domestic product in country $j$, de-trended with the HodrickPresscott filter. 
A positive value of the BCS coefficient points to the existence of business cycle synchronization in two countries $i$ and $j$. On the other hand, a negative value of the BCS coefficient denotes a lack of business cycle synchronization between countries $i$ and $j$.

The intensity of trade, on the other hand, is measured with the Trade Intensity Index (TII) developed by Drysdel, Garnaut (1993), and Yeats (1997), which is expressed by the following equation:

$T I I_{i j} \frac{\left(\frac{i j}{i w}\right)}{\left(\frac{j w}{w w}\right)}$

where:

$\left(X_{i j} / X_{i w}\right)$ - the ratio of export of country $i$ to country $j$ to the total export of country $i$;

$\left(M_{j w} / M_{w w}\right)$ - the ratio of the total import of county $j$ to the total world's import.

The trade intensity index is employed to determine whether the value of trade between two countries is larger or smaller than might be expected on the basis of their importance to global trade. The index can take a value larger or smaller than one. A value larger (smaller) than one indicates that bilateral trade is larger (smaller) than expected, considering the significance of the trade partner in global trade.

Next, the formulation of the degree of adjustment of the structure of countries' export supply to the structure of their import demand influences the development of countries' economic complementarity and the intensity of intra-industry trade. This influence is related to the so-called complementarity index of the exporter ( $S e$ ), which is the sum of the absolute difference between the proportions of imports and exports (according to a SITC three-digit classification) in countries under analysis, divided by two.

$S e_{j k}=1-\frac{\sum_{i}\left|E_{i j}-M_{j k}\right|}{2}$

$S e_{j k}$ - complementarity index of exporter $j$ in relation to importer $k$;

$i$ - commodity group according to the SITC threedigit classification;

$j$ - exporter (group of countries or a country); $k$-importer (group of countries or a country);

$E_{i j}$ - the proportion of commodity group $i$ in the total export of country $j$;

$M_{i k}$ - the proportion of commodity group $i$ in the total import of country $k$.

An exporter's trade complementarity index may take values between 0 and 1 . If the value of the index is zero, it denotes that there is no relationship between the structure of country $j$ 's exports and country $k$ 's imports. If, however, the value of the index is 1 , the two countries' export and import structures are perfectly matched.

To analyze the influence of the level of trade intensity on the synchronization of business cycles in Poland and the European Union and in Poland and the Euro Zone between 1995 and 2011, two models based on Frankel and Rose's (1998) model have been employed. They are formulated as follows:

$\operatorname{Corr}_{P L_{-} E U}=c+\alpha T I I_{E U}+S e_{E U}+\varepsilon_{E U}$

$\operatorname{Corr}_{P L_{-} \text {Euro }}=c+\alpha T I I_{\text {Euro }}+S e_{\text {Euro }}+\varepsilon_{\text {Euro }}$

where:

Corr $_{P L_{E} E U}$ - index of business cycle synchronization in Poland and the European Union;

$T I I_{E U}$ - trade intensity index between Poland and the European Union;

$S E_{E U}$ - trade complementarity index of Poland in relation to the European Union;

Corr $_{P L_{-} E u r o}$ - index of business cycle synchronization in Poland and the Euro Zone;

$T I I_{\text {Euro }}$ - trade intensity index between Poland and the Euro Zone;

$S E_{\text {Euro }}$ - trade complementarity index of Poland in relation to the Euro Zone.

All of the above variables have an annual frequency and were measured in the period between 1995 and 2011. As presented in the figure below, the indices of business cycle synchronization for Poland and the European Union were positive in most years between 1995 and 2011, which points to the conclusion that the degree of business cycle synchronization in Poland and the European Union is quite significant. Conversely, negative index values for business cycle synchronization suggest that a lack of synchronization was mainly present in the periods of economic slowdown caused by economic crises [Fig. 3]. 

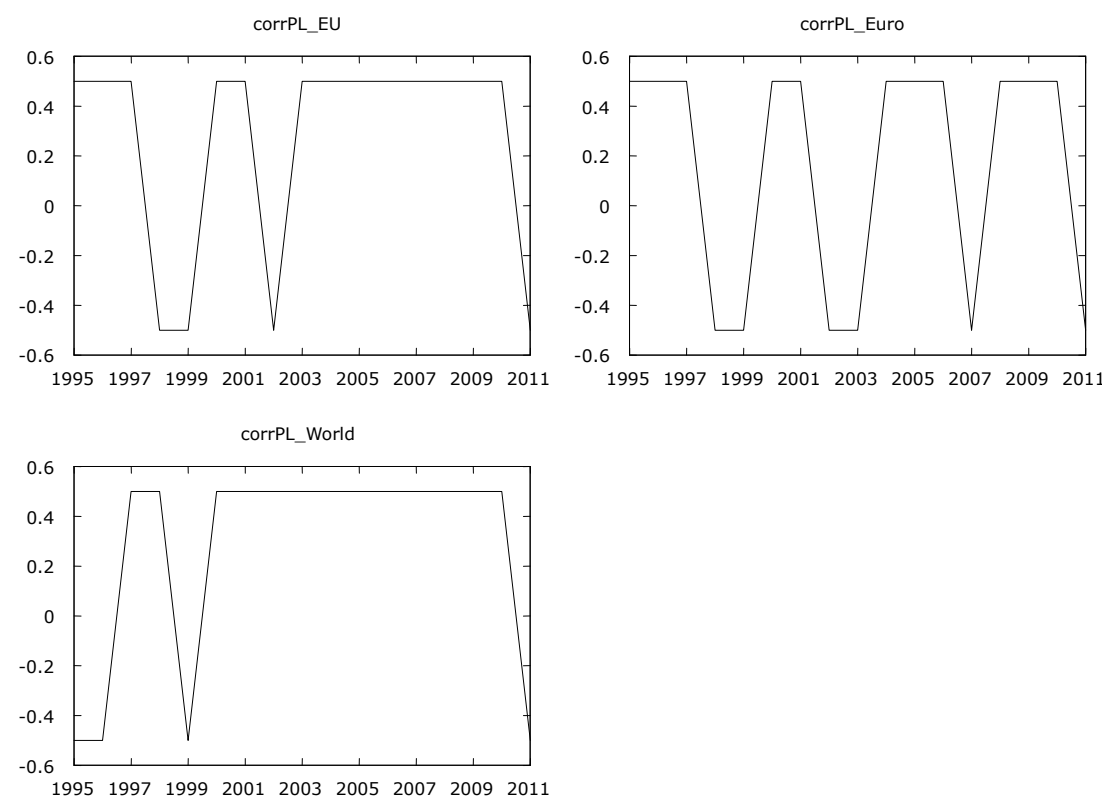

Figure 3. Coefficients of business cycle synchronization (BCS) in Poland and the European Union, and in the Euro Zone and the world, between 1995 and 2011 (UNCTAD, 2012).

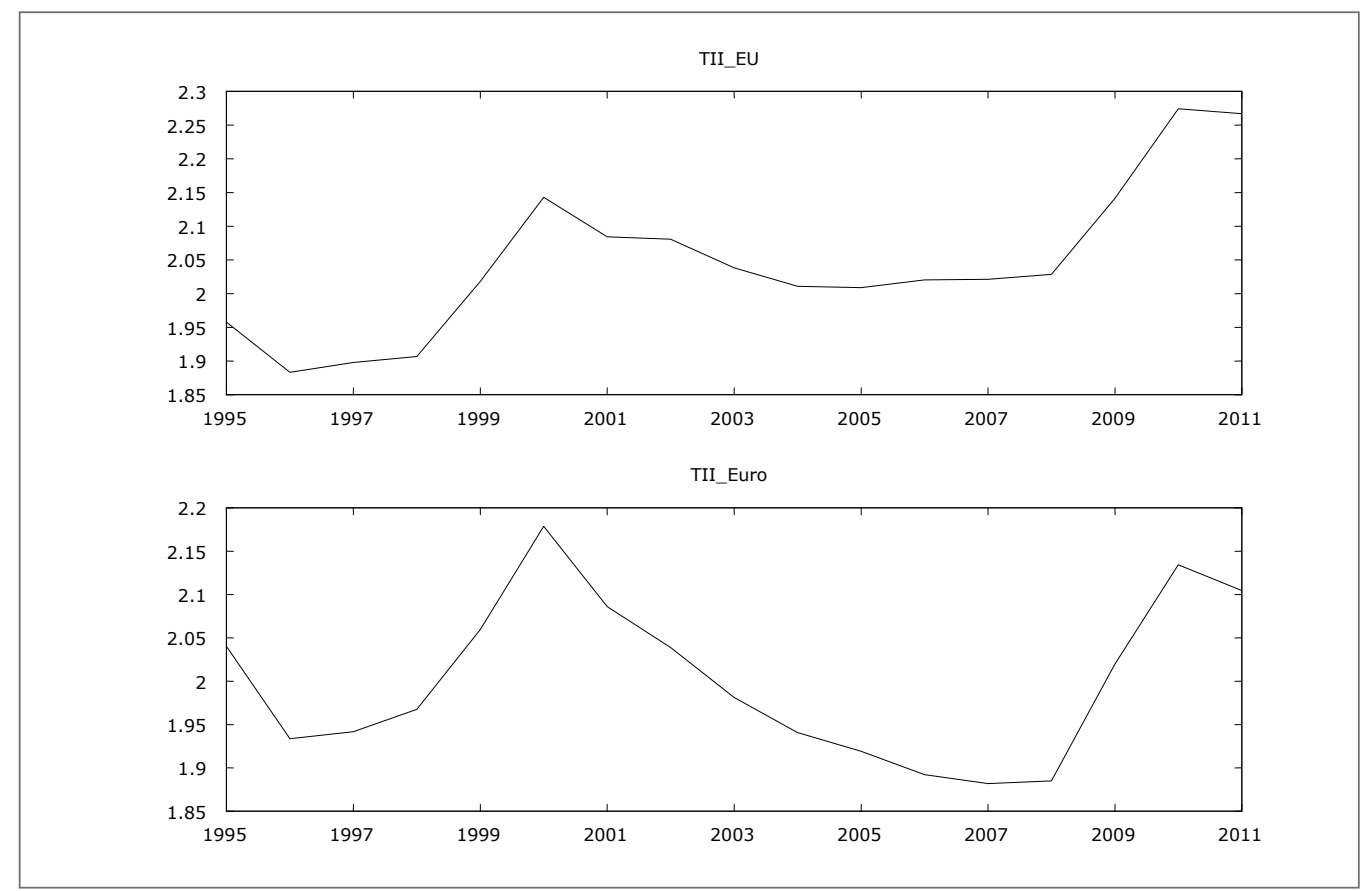

Figure 3. Indices of trade intensity (TII) of Poland and the European Union, and the Euro Zone and the world, between 1995 and 2011 (UNCTAD, 2012). 

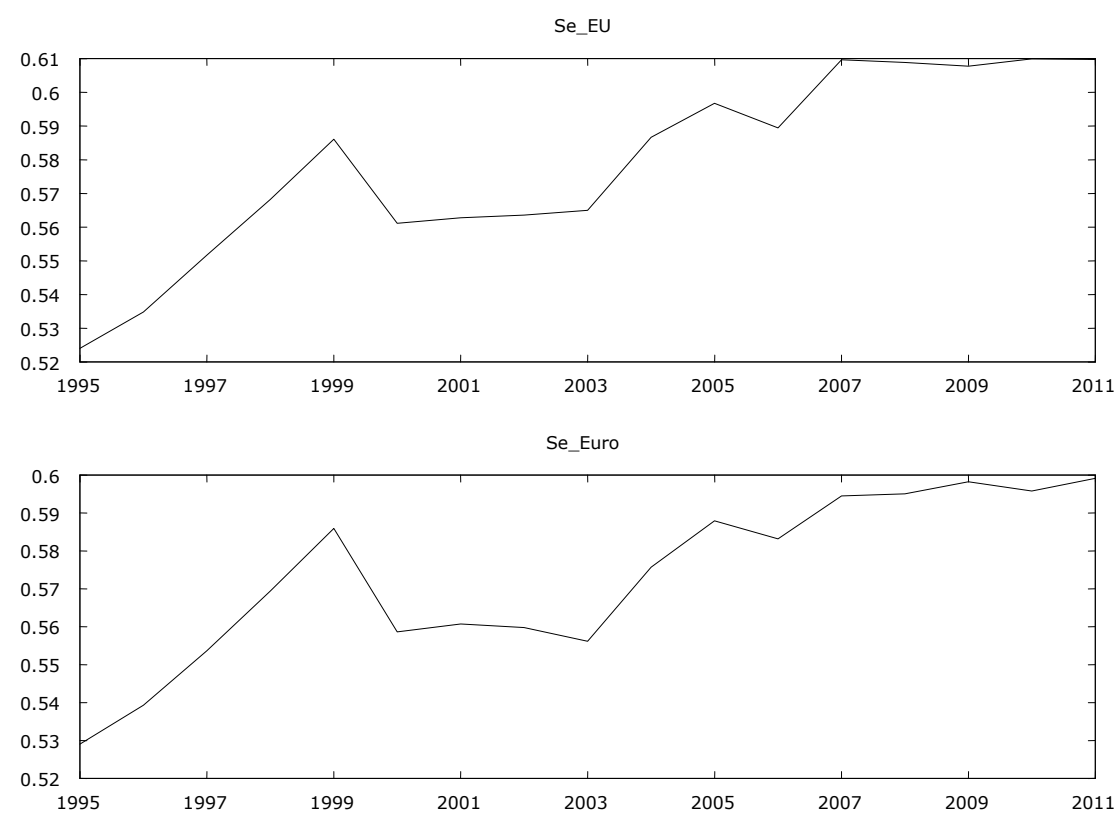

Figure 3. Trade complementarity indices (Se) of Poland, the European Union, and the Euro Zone between 1995 and 2011 (UNCTAD, 2012).

The business cycle synchronization indices for Poland and the Euro Zone, however, are formulated in a subtly different way. In this case, the lack of business cycle synchronization in Poland and the Euro Zone was considerably more frequent than in the case of the European Union.

As presented in the figure below, the intensity of trade between Poland and the European Union generally increased in the period between 1995 and 2011, with the peak observable during the last three years of the period in question. In contrast, the fluctuations in the intensity of trade between Poland and the Euro Zone were different. The trade intensity index was highly variable in this case. The value of the index increased rapidly until the year 2000 when it was considerably adjusted, and its value began to decrease until 2007. Another period of growth in the trade intensity between Poland and the Euro Zone began in 2008 [Fig. 4].

Analyzing the changes undergone by the trade complementarity index of Poland and the European Union and the Euro Zone between 1995 and 2001, one may note a gradual increase in the values of the indices in the period under analysis, excluding 2000-2003, which testifies to a greater intensity of intra-industry trade between the economies in question [Fig. 5].

It was necessary to determine the stationarity of the time series employed in the study prior to running the models because, if the possible lack of time series stationarity was not taken into account, it could have led to the emergence of a spurious regression between the variables. Therefore, the Augmented Dickey-Fuller (ADF) test was performed. The results of the augmented ADF test revealed the existence of time series integrated of orders 0 and 1 . The relevant outcomes of the ADF test are presented in the table below [Tab. 1].

The lack of stationarity of several time series included in the models compelled us to modify the models' functional forms. The modification of the autoregressive vector consisted of interchanging the values of the analyzed variables with their first differences. Simultaneously, due to the lack of a unit root in any of the time series and the lack of cointegration between the variables in the model, there was no possibility of augmenting and transforming the models into vector error correction models. 
Table 1. The results of analysis of stationarity of particular time series in the VAR model

\begin{tabular}{lc}
\hline Time series & order of integration \\
\hline CorrPL_EUt - index of business cycle synchronization between Poland and the European Union & $I(0)$ \\
TIIEUt - trade intensity index between Poland and the European Union & $I(1)$ \\
SeEUt - trade complementarity index of Poland in relation to the European Union & $I(1)$ \\
CorrPL_Eurot - index of business cycle synchronization between Poland and the Euro Zone & $I(0)$ \\
TIIEurot - trade intensity index between Poland and the Euro Zone & $I(0)$ \\
SeEurot - trade complementarity index of Poland in relation to the Euro Zone & $I(1)$ \\
\hline
\end{tabular}

Table 2. The VAR System (Vector Autoregression Model), lag order 1. CLS estimation for 1996-2011

\begin{tabular}{|c|c|c|c|}
\hline \multicolumn{4}{|c|}{ Equation 1: corrPL_EU } \\
\hline & \multicolumn{2}{|c|}{ Coefficient } & t-Student \\
\hline corrPL_EU_1 & \multicolumn{2}{|c|}{0.11326} & 0.340418 \\
\hline TII_EU_1 & \multicolumn{2}{|c|}{-0.609078} & -1.29091 \\
\hline Se_EU_1 & \multicolumn{2}{|c|}{2.51828} & 4.53386 \\
\hline Arith.mean.of.depenent.variable & 0.250000 & Stand.devia.of.pred.variab & 0.447214 \\
\hline Sum of squares of residuals & 2.916527 & Stand. error of residuals & 0.473654 \\
\hline Coefficient.of.determination.R2 & 0.270868 & Corrected R2 & 0.158694 \\
\hline$F(3,13)$ & 1.609809 & F-test value & 0.235149 \\
\hline Autocorrelat. of residuals - rho1 & -0.019653 & Durbin-Watson Statistic & 1.826721 \\
\hline \multicolumn{4}{|c|}{ Equation 2: corrPL_Euro } \\
\hline & \multicolumn{2}{|c|}{ Coefficient } & t-Student \\
\hline corrPL_Euro_1 & \multicolumn{2}{|c|}{0,0474545} & 0,285766 \\
\hline TII_Euro_1 & \multicolumn{2}{|c|}{$-0,479385$} & $-1,0167$ \\
\hline Se_Euro_1 & \multicolumn{2}{|c|}{1,87404} & 3,50154 \\
\hline Arith.mean.of.depe.variable & 0.125000 & Stand.devia.of.pred.variab & 0.500000 \\
\hline Sum of squares of residuals & 3.687653 & Stand. error of residuals & 0.532603 \\
\hline Coefficient.of.determina.R2 & 0.278087 & Corrected R2 & 0.163746 \\
\hline$F(3,13)$ & 0.367036 & F-test value & 0.778021 \\
\hline Autocorrel.of.residuals-rho1 & -0.047473 & Durbin-Watson Statistic & 1.923755 \\
\hline
\end{tabular}

In the analysis, a single time lag between predictor variables and the dependent variable (one year) was adopted. The selected lag order was compliant with the results of the Akaike, Schwartz Bayesian, and Hannan-Quinn Information Criteria. The model with one lag had the largest information capacity under these criteria.
Next, the models were estimated using the Vector Autoregression Model proposed by Sims (1980). The VAR method consists of analyzing a given phenomenon using a system of equations, which, according to Sims (1980), eliminates the problem of predictor variables' exogeneity. The results of the 


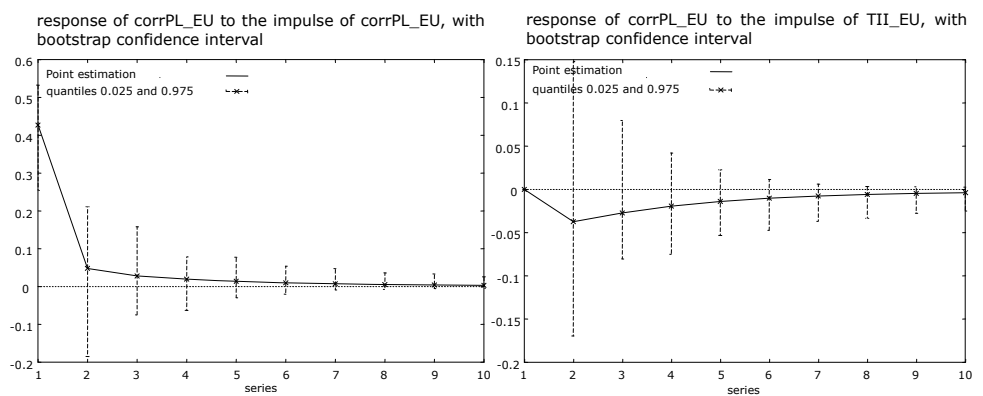

response of corrPL_EU to the impulse of Se_EU, with bootstrap confidence interval

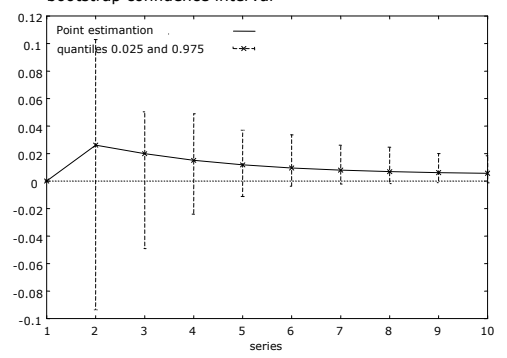

Figure 6. Graphs of the impulse response function of the business cycle synchronization indices of Poland and the European Union

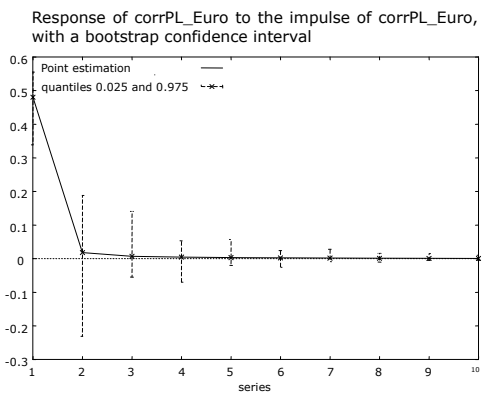

response of corrPL_Euro to the impulse of TII_Euro, with a bootstrap confidence interval

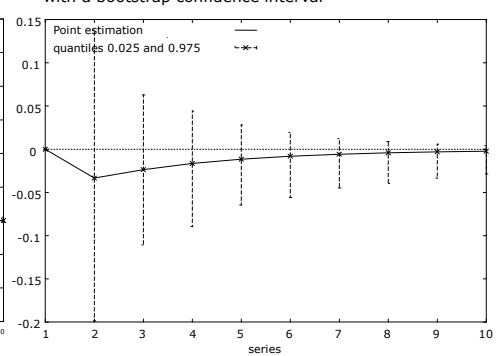

Response to corrPL_Euro to the impulse of Se_Euro, with a bootstrap confidence interval

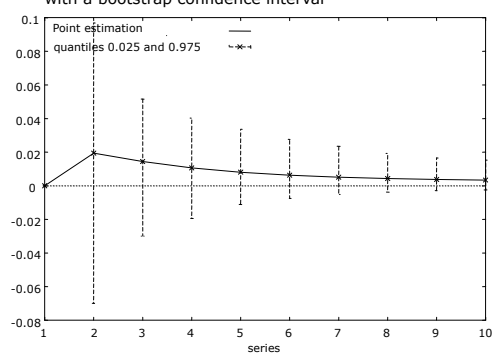

Figure 7. Graphs of the impulse response function of the business cycle synchronization index and the Euro Zone 
parameter estimation in the VAR model are presented below [Tab. 2].

Based on the results of the estimation of equation 1, the synchronization of the Polish and European Union's business cycles in the period under analysis was clearly determined by the intensity of trade and trade complementarity between Poland and the European Union. The estimated coefficient of the influence of trade intensity on business cycle convergence amounted to -0.61 , thus confirming the negative influence of trade on the correlation of business cycles between Poland and the European Union. However, the coefficient of the influence of trade complementarity on business cycle synchronization was 2.52 , which testified to the positive influence of intra-industry trade on the business cycle convergence of the economies in question.

The estimation of equation 2 produced analogous results. Indeed, according to the data presented in table 2 , the business cycle synchronization between Poland and the Euro Zone was also considerably dependent on trade intensity and complementarity between Poland and the Euro Zone. In this case, the coefficient of the influence of trade on business cycle convergence was -0.48 , which suggested a negative impact of trade on the business cycle correlation between Poland and the Euro Zone . Contrastingly, the coefficient of the influence of trade complementarity on business cycle synchronization amounted to 1.87 , indicating that the influence of intra-industry trade on the business cycle convergence of Poland and the Euro Zone is positive.

Consequently, it is apparent that the results of the conducted research are in compliance with the theory claiming a negative (positive) influence of inter-industry (intra-industry) trade on business cycle synchronization in the countries under analysis. The results obtained from the study are also in agreement with the results of empirical research carried out by Camacho, et al. (2006); Shin and Wang (2003).

The next phase of research was concerned with measuring the significance of the analyzed coefficients' influence on the synchronization of business cycles in Poland, the European Union, and the Euro Zone in the period between 1995 and 2011. The measurement was performed using the so-called impulse response function, i.e., a function of a response of a business cycle synchronization index to an impulse in the form of a change in the indices of trade intensity and complementarity between Poland and the European Union and Poland and the Euro Zone [Fig. 6 and 7].

On the basis of the figures presented above, it may be concluded that the shock increase in the index of business cycle synchronization in Poland and the European Union led to an immediate rise in the value of this index in the first year after the shock occurred, and later, to a decrease and gradual stabilization over the course of the next four years. The increase in the intensity of trade between Poland and the European Union led to a gradual fall in the index of business cycle synchronization for the economies under analysis in the two successive years after the shock occurred and to a gradual increase and stabilization in the next six years. The response of the business cycle synchronization index for Poland and the European Union to the increase in the trade complementarity index of the analyzed economies was different, however. Namely, the shock increase in the value of the trade complementarity index led to a gradual rise in the business cycle synchronization index for Poland and the European Union, and subsequently to a gradual fall and stabilization over the five successive years.

Identically, analyzing the figures provided above allows us to assert that the shock increase in the business cycle synchronization index of Poland and the Euro Zone caused an immediate increase in the value of this index in the first year before the shock emerged and led to a dramatic drop and stabilization in the second year following the shock. In contrast, the gain in the trade intensity index between Poland and the Euro Zone led to a progressive fall in the business cycle synchronization index of these economies for two successive years after the occurrence of the shock, and later, to a gradual increase and stabilization over the next five years. Contrastingly, the shock increase in the value of the trade complementarity index for Poland and the Euro Zone caused a gradual rise in the business cycle synchronization index of the above-mentioned economies for two successive years after the shock and led to a progressive fall and stabilization over the next four years.

\section{Conclusion}

The empirical study carried out in this paper was concerned with the influence of international trade on the 
synchronization of business cycles in Poland and the European Union and in Poland and the Euro Zone . It allowed us to draw the conclusion that an increase in trade turnover does not necessarily lead to a rise in business cycle synchronization in the economies under analysis. The influence of the increase in trade between two countries on business cycle synchronization depends predominantly on the structure of trade turnover and not solely on the intensity of trade.

A rise in trade causes greater business cycle convergence only in the case of intra-industry trade, which leads to an increase in the complementarity of countries' economic structures and contributes to the emergence of symmetric economic shocks. Otherwise, the increase in trade turnover of two economies may cause further specialization in a country and lead to an occurrence of frequent idiosyncratic (asymmetric) shocks.

The results of this study carry profound implications from the perspective of Poland's accession to the Euro Zone. Notably, because the increase in intra-industry trade between Poland and the Euro Zone leads to greater business cycle correlation for both these economies, the cost related to the lack of an autonomous monetary policy in the face of idiosyncratic economic shocks will be lower in the case of Poland's accession to the monetary union. Therefore, the net benefit arising from Poland's accession to the monetary union will turn out to be higher under conditions of rising levels of complementarity in economic structures between Poland and the Euro Zone. Hence, the outcome of the present study may constitute a compelling arguments advocating Poland's pursuit of full participation in the monetary union of the EU member states.

\section{References}

Akin, C. (2006). Multiple Determinants of Business Cycle Synchronization. Unpublished manuscript, Department of Economics, George Washington University, Washington, DC, USA

Bayoumi, T., \& Eichengreen B. (1992). Shocking Aspects of European Monetary Unification (Working Paper No. 3949). National Bureau of Economic Research.

Calderón, C., Chong, A., \& Stein, E. (2002). Trade Intensity and Business Cycle Synchronization: Are Developing Countries Any Different? (Working Papers No. 195). Central Bank of Chile.
Camacho, M., Perez-Quiros, G., \& Saiz, L. (2006). Are European business cycles close enough to be just one? Journal of Economics Dynamics and Control, 30 (9-10), 1687-1706.

De Haan, J, Inklaar, R. C., \& Jong-A-Pin, R. M. (2008). Will business cycles in the Euro area converge? A critical survey of empirical research. Journal of Economic Surveys, 22 (2), 234-273.

De Haan, J., Inklaar, R., \& Jong-a-Pin, R. M. (2005). Trade and Business Cycle Synchronization in OECD Countries - A re-examination (Working Paper Series No. 1546). CESifo Group Munich.

Drysdel, P., \& Garnaut, R. (1993). The Pacific: An Application of General Theory of Economic Integration. In F. Bergsten, M. Noland (Eds.), Pacific Dynamism and International Economic System. (pp. 183-223). Washington, DC: Institute for International Economics.

Frankel, J. A. \& Rose, A. K. (1998). The Endogeneity of the Optimum Currency Area Criteria. The Economic Journal, 108 (449), 1009-1025.

Grigoli, F. (2011). The Impact of Trade Integration on Business Cycle Synchronization for Mercosur Countries. The European Journal of Comparative Economics, 9 (1), 103-131.

Imbs, J. (2004). Trade, Finance, Specialization, and Synchronization. The Review of Economics and Statistics, 86 (3), 723-734.

Karimi, F., Pirasteh, H. (2009). Relationship between Economic Integration and Business Cycle Synchronization. International Journal of Business and Development Studies, 1 (1), 67-82.

Kenen, P. B. (1969). The Optimum Currency Area: An Eclectic View. In R. Mundell \& A. K. Swoboda (Eds.), Monetary Problems of the International Economy (pp. 41-60). Chicago, IL: University of Chicago Press.

Kenen, P. B. (2000). Currency Areas, Policy Domains and the Institutionalization of Fixed Exchange Rates (Discussion Papers No. 0467). Centre for Economic Performance, London School of Economics and Political Science.

Kose, M. A., Yi, K. M. (2005). Can the Standard International Business Cycle Model Explain the Relation Between Trade and Comovement? (Working Paper No. 05-3). Federal Reserve Bank of Philadelphia. 
Krugman, P. R. (1991). Geography and Trade. Cambridge, MA: MIT Press.

Lubiński, M. (2007). Międzynarodowy cykl koniunkturalny [International Business Cycle]. Contemporary Economics, 1 (2), 5-19.

Rana, P. B., Cheng, T., Chia, W. M. (2011). Trade Intensity and Business Cycle Synchronization: East Asia versus Europe. Journal of Asian Economics, 23 (6), 701-706.

Shin, K., Wang, Y. (2003). Trade Integration and Business Cycle Synchronisation in East Asia. (Discussion Paper No. 574). The Institute of Social and Economic Research.

Sims. C. A. (1980). Macroeconomics and Reality. Econometrica, 48 (1), 1-48.

UNCTAD (2012). UNCTAD Handbook of Statistics. New York, NY: United Nations

Yeats, A. J. (1997). Does MERCOSUR Trade Performance Raise Concerns About The Effects of Regional Trade Arrangements? The World Bank Economic Review, 12 (1), 1-28. 
Appendix 1: The rate of the real GDP in Poland, in the world, in the EU, and in the Euro Zone between 1995 and 2011 [expressed in \%] (UNCTAD, 2012).

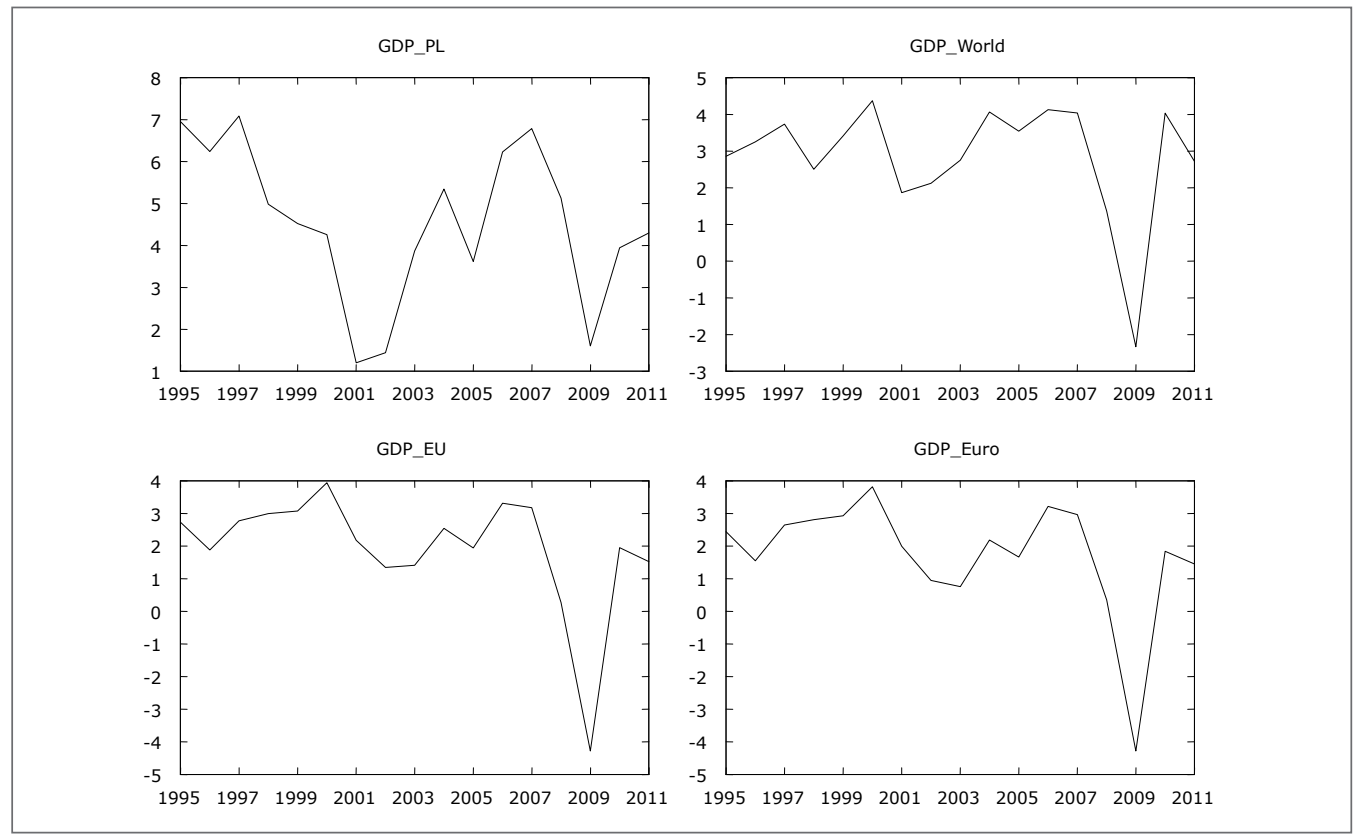

Appendix 2: The value of total Polish exports in relation to the European Union and the Euro Zone [expressed in billion USD] (UNCTAD, 2012).
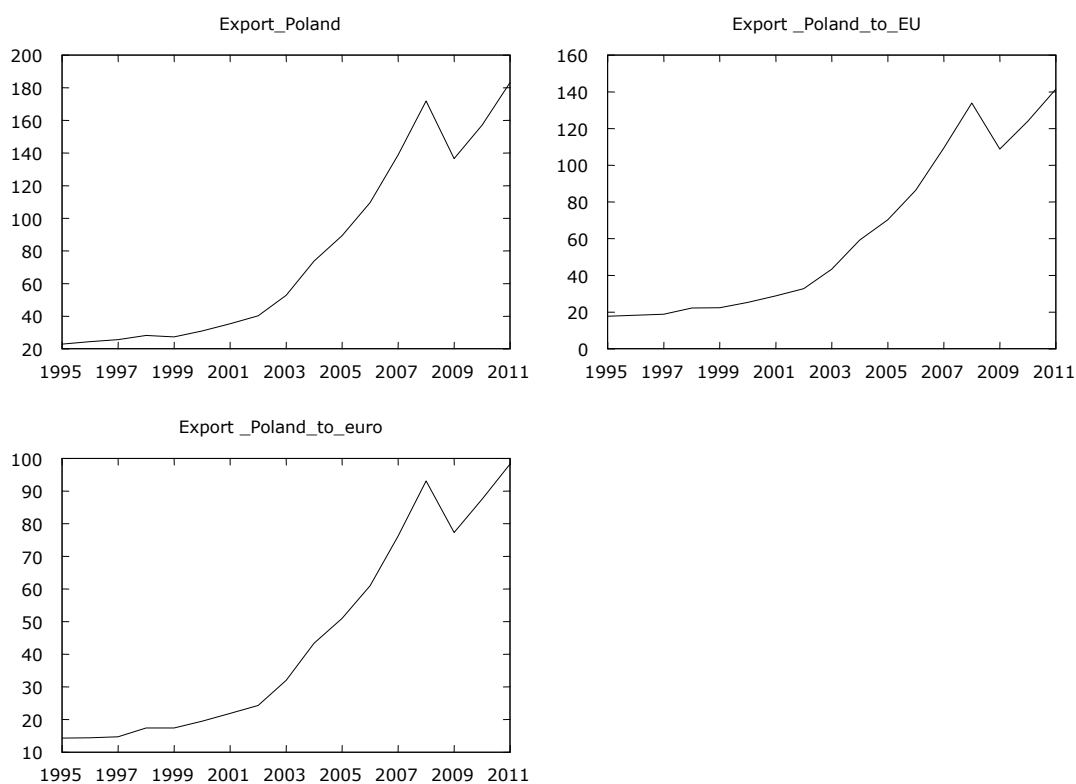
